\title{
Research and practice of new technology and teacher education fusion mode under the future education space station
}

\author{
Kong Yiquan \\ Research Center for Teacher Education in Western \\ Guangdong \\ Lingnan Normal University, Zhanjiang, Guangdong 524048, \\ China \\ 20693458@qq.com
}

\author{
Wu Tao \\ Digital Learning Engineering Technology Development \\ Center of Guangdong College \\ Lingnan Normal University, Zhanjiang, Guangdong 524048, \\ China \\ freemankyq@163.com
}

\begin{abstract}
This paper analyzed the definition of the integration of new technology and teacher education in the future education space station, and discusses the new technology and the depth of the integration of the teacher education connotation. And then from the perspective of process division dimension fusion of new technology and teacher education, build the future educational space station "new technology and teacher education integration mode is established. Finally, the scientific evaluation model sustained track record and evaluate the quality of the sample data.
\end{abstract}

Keywords-teacher education; new technology; fusion mode; future education;

\section{INTRODUCTION}

With the advent of the third industrial revolution, we have entered a new era. Human education is divided into three reforms. The first time is the agricultural society's transformation, was separated from the primitive individual education to enter personalized the agriculture education, namely the private school educated. The second time is the Industrial Revolution human society starts to enter the scale type development and standardized the flow process manufacture process. This time, the education also starts the formalization and the flow process. Because all defers to the standardized education which the industrialization flow carries on, therefore, raises the student presents the homogenization characteristic, this education way was tallies with the time characteristic then. After enters the third Industrial Revolution, the society entered personalized production, the manufacture time, the need more innovation talented person and the personalized education. The personalized education is a samsara, is a large-scale personalized education. However, the current education in the space-time dislocation, the education system is still in the industrialized era. The scale, batch and standardization education have been out of line with our times and the students are not required by the society. On the other hand, the society needs the talented person school could not supply actually, this has created the employment pressure. What type the third Industrial Revolution does need talented person? Is adapts the high end innovation talented person and the high quality skill talented person who the third Industrial
Revolution needs. Normal University is the school that raises the future teachers, how to use the new technology in the teaching situation, how to train the future teachers, achievements of the future education? This is not only our confusion, but also a rare opportunity; higher education is facing innovation, education informatization has become a research hotspot.

\section{THE IMPORTANCE OF NEW TECHNOLOGY AND TEACHER EDUCATION FUSION MODE}

With the information technology as the representative of the technological revolution swept the globe, education information has been upgraded to the height of the national strategy. In 2014, the Ministry of Education, Ministry of Finance and so on five ministries and commissions appear the related document, integrates the education informationization the national education special direction content [1]. The national medium and long-term education reformed and develops in the plan summary to manifest the technical function, by the technical actuation reform, has been clear about the education informationization importance. The information technology has revolutionary influence on the development of education, must be highly valued. The traditional mode of education has been difficult to cultivate the talent needed for the third industrial revolution. If you want to let the students in the third industrial revolution survive and get to work, it is necessary to let them have the corresponding professional skills. Therefore our schools need to change, to adapt to the learning environment. Cloud computing, Internet of things, intelligent terminal is the future of education three information technology innovation. With cloud computing, 3D Print, Internet, and other emerging technologies, and build research and production resource sharing among, intelligent, flexible teaching and learning environment [2]. Educational Development with a revolutionary impact of the new technologies in teacher education has an important role.

First, educates the new technology in the teacher has the revolutionary influence to learner's study way and the life style.

The current information technology intellectualized degree is more and more high, including the abundant guest, 
broadcasts the guest, micro abundantly, immediate communication, Vicky hundred branches and so on social the software new technology development, caused the independent study, the personalized study, to exude in the study and so on the new study way educates the domain in the teacher already to become the reality. The emergence of new concepts such as the Internet of things and the triple play provides a wider development space for modern teacher education. Secondly, the new technology has revolutionary influence on the reform of the educational reform of the teacher education and the reform of the personnel training mode. The new information technology is strongly supported by the extensive learning, personalized learning, collaborative learning, and online formative assessment and so on. The innovation of personnel training mode, the quality of education and the reform of the talent evaluation system can be opened through the means of technology. According to the educational process development needs, from education, instructional design, educational and other aspects of information organization, around the psychological needs of the fully integrated technical, according to education and technology orientation awareness, use technology to gather the relevant educational elements, needed for integration into its education technology culture.

\section{THE INTEGRATION OF NEW TECHNOLOGY AND TEACHER EDUCATION IN THE FUTURE AND THE ANALYSIS OF THE MULTI- DIMENSIONAL STRUCTURE}

Based on the domestic and foreign research results analysis of the integration of new technology and teacher education viewpoint is defined, we investigate new technology and teacher education, the integration of connotation, and based on the process perspective division new technology and education fusion dimensions. We construct a multidimensional structure pattern of integration of new technology and teacher education. Firstly, Information technology integration division of breadth and depth, the depth of information technology and education organizations of different state of the interaction degree is defined as the information technology integration, and interactive mode from quantitative change to qualitative evolution is the information technology fusion depth of the upgrade process. Secondly, organic information technology fusion is that after the adoption of the education of information technology, in order to give full play to the potential of information technology, to the elements and information system of moderate adjustment, make to each other organically coordinated as a whole fusion way. Thirdly, after the adoption of information technology, the innovative integration of information technology is based on the experience of its growing accumulation of information technology, and the development and use of information technology to complete innovative education mode.

\section{CONSTRUCTION OF THE FUSION MODE BETWEEN THE THREE EDUCATIONAL, SPACE AND TECHNOLOGY}

The three aspects of education, space, technology, and interaction, and these three aspects form an iterative cycle. When we start from any of them, we must consider the impact and support of the remaining two.. In addition, the pattern is based on the life cycle of the learning space, respectively from the education, space and technology details of the concept and design of two stages should be specifically considered. We should consider the following questions concretely. What learning styles are you trying to learn through design space? Why such learning space can affect the learning, whether there is theoretical basis and other relevant evidence? Is there a plan for revising the course to take advantage of the new facility in learning space? How to carry out the teaching and training to the normal students? Education-Space-Technology mode is in Fig.1.

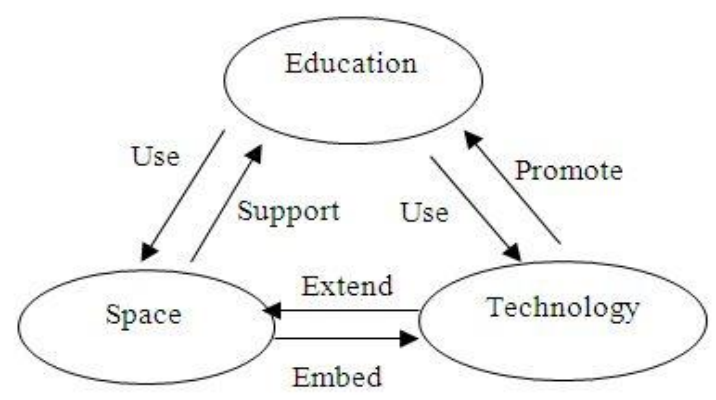

Fig. 1. Education-Space-Technology mode

\section{CONSTRUCTING A NEW TYPE OF TEACHER EDUCATION IN THE CHARACTERISTICS OF AUTONOMOUS, INQUIRY AND COOPERATION}

In experimental teaching, we combine related new technologies, try to change the traditional classroom teaching structure, the teachers dominate the classroom with the teacher as the center, the traditional classroom teaching structure, can give full play to the leading role of the teacher, and highlight the subject status of students in the classroom teaching structure [3]. Figure.2 shows the capability of the Web to support these modalities.

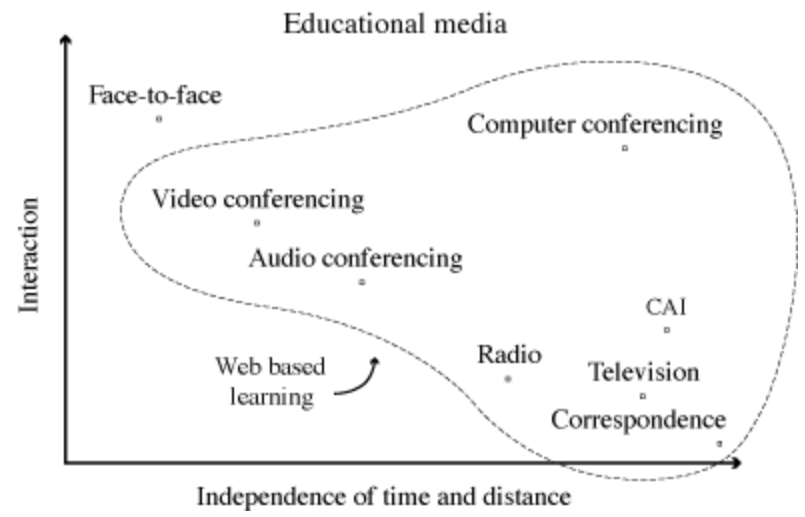

Fig. 2. Educational media subsumed by the web

We carry out the process of implementing this response; it is the process of the depth of the integration of information technology and education. This fusion process includes a wealth of information resources (such as subject special subject website, resource base, case, $\mathrm{CD}$, etc.).Teaching media to by teachers to help break through the key, difficulty visualizing teaching tool, change is to assist teachers in teaching tools, and promote students' autonomous learning of cognitive tools, collaboration tool for communication and emotional experience and internalization of tools. The integration of new technology 
and teacher education in the future and the analysis of the multi-dimensional structure with the information technology as the representative of the technological revolution swept the globe; education information has been upgraded to the height of the national strategy. In 2014, the Ministry of Education, Ministry of Finance and so on five ministries and commissions appear the related document, integrates the education informationization the national education special direction content. The national medium and long-term education reformed and develops in the plan summary to manifest the technical function, by the technical actuation reform, has been clear about the education informationization importance. The information technology has revolutionary influence on the development.

\section{VI.THREE DIMENSIONS OF NEW TECHNOLOGY AND TEACHER EDUCATION INTEGRATION MODE}

The new technology and teacher education fusion mode contains the three dimensions of the breadth, depth and level. The breadth of the integration of new technology and teacher education mainly reflects the diffusion in the range and depth of new technology and teacher education integration is mainly reflected in the application of the evolution of, administrative levels is reflected in the penetration of information technology and the different system activities and fusion. These three dimensions have the obvious difference, first they separately have manifested the fusion different side, in which breadth and the depth more have manifested new technical and the education fusion procedure and the dynamic, but level Uygur then more has manifested the information technology fusion in the management complexity. The fusion of the three dimensions is influenced by the different factors. Hierarchy dimension-Breadth dimension-Depth dimension mode is in Fig.3.

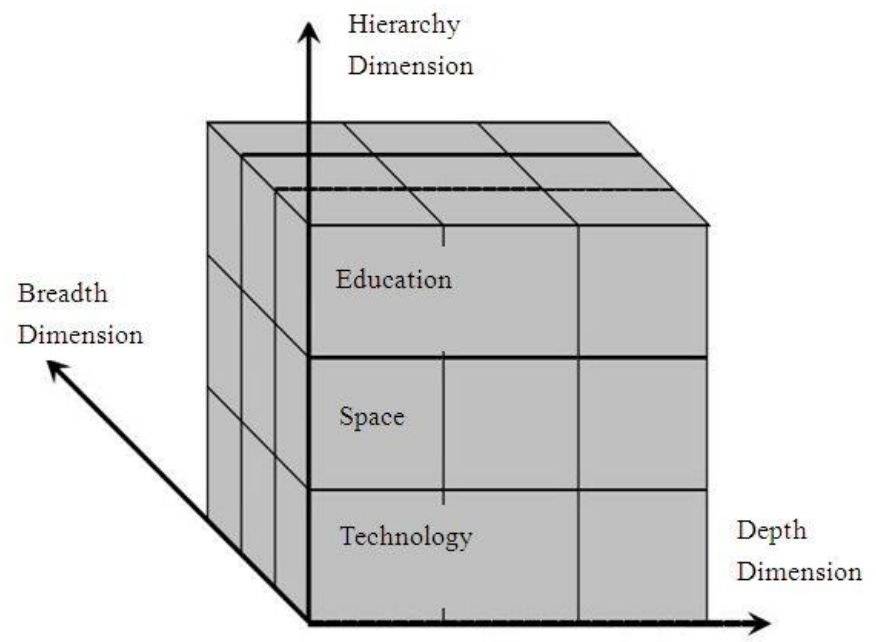

Fig. 3. Hierarchy dimension-B readth dimension-Depth dimension mode

The environment of education is an education- centered and multi- environmental system, controlling and regulating the production, existence and development of education [4]. The deep integration of information technology and education and teaching embeds in every element of educational system and plays a supporting role in the work of the whole system.
VII. EXPERIMENTAL TECHNOLOGY APPLICATION OF NEW TECHNOLOGY AND TEACHER EDUCATION FUSION MODE

Technology application of new technology and teacher education fusion mode used semantic web. The semantic web will be populated by a variety of autonomous agents - small computer programs designed to navigate the Web, searching for particular information and then acting on that information in support of their assigned task. In education, student agents will be used for intelligent searching of relevant content, and as secretaries for booking and arranging for collaborative meetings, for reminding students of deadlines, and for negotiating with the agents of other students for assistance, collaboration, or socialization. Teacher agents will be used to provide remedial tuition, and to assist with record keeping, with monitoring student progress, and even with marking and responding to student communications. Content itself can be augmented with agents that control rights to its use, automatically update it, and track the means by which the content is used by students.

One added benefit of using the Semantic Web as a basis for the Conceptual Web is application-independence [5]. Just as the Semantic Web gives the machine (software agents and applications alike) a sort of "sixth sense" about the meaning of web resources, the conceptual web gives the human user a sixth sense about the conceptual context and the underlying meaning of the current situation, which is independent of the currently used application. We are therefore studying ways to introduce the Conceptual Web into other environments. Apart from their usage on the ordinary web, we are investigating the fascinating possibility of introducing conceptual structures in 3D environments. A 3D environment filled with semantics and conceptual structures would present a fundamentally different experience, enabling for the first time a virtual reality full of meaning, and not only packed with dead 3D objects whose meaning is defined by the graphics engine. This semantics could even be accessed from outside such an environment, making the 3D environment fully semantically transparent. Technology structure of Semantic Web is in Fig.4.

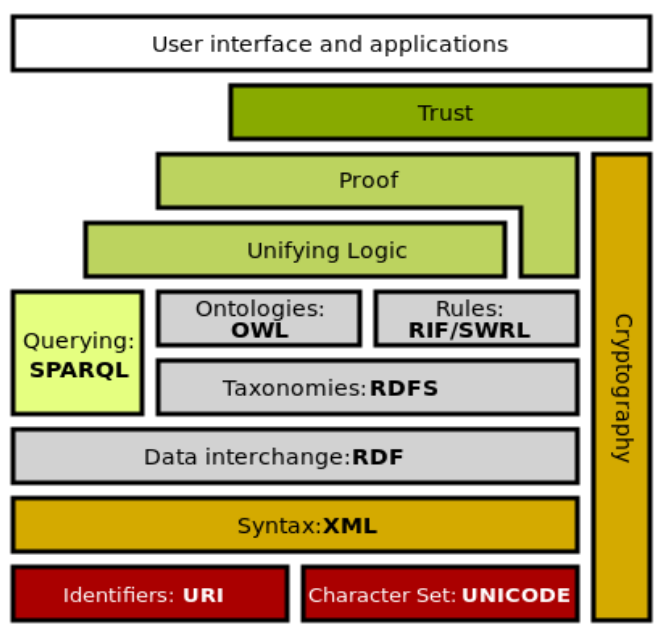

Fig. 4. Technology structure of Semantic Web

The challenge for teachers and course developers working in an online learning context is to construct a learning 
environment that is simultaneously learning centered, content centered, community centered, and assessment centered [6]. There is no single, right medium of online learning, or a formulaic specification that dictates the kind of interaction most conducive to learning in all domains with all learners. Rather, teachers must learn to develop their skills so that they can respond to student and curriculum needs by developing a set of online learning activities that are adaptable to diverse student needs.

\section{VIII.EXPERIMENTAL DATA ANALYSIS OF NEW TECHNOLOGY AND TEACHER EDUCATION FUSION MODE}

The project acquired through experimental teaching reform, the establishment of a scientific mode of assessment, an ongoing track record. Based on sample data for the teaching quality assessment, test the reliability and validity of scales, information technology research and analysis variables and effect of background variables on them, We are based on the sample data, correlation analysis, multiple regression analysis and structural equation modeling analysis of information technology relationship with the variables in the model, verify the authenticity of assumptions, then schema validation results are summarized and discussed. Currently, the big data era has arrived and the field of education also has accumulated huge amounts of data. In the field of education, more and more software systems have been deployed and there stores massive educational data. How could we fully use the massive educational data and transfer the data into useful information and knowledge in order to make scientific educational decision and optimize instruction has become the content concerned by educators and learners.

Learning analytics could be used for realizing the value of learning process data. We used domestic and foreign current studies of learning analytics, summed up the key technology and analytical model of learning analytics, and with three examples respectively from different user's perspective including administrators, tutors and learners; demonstrate application process of learning analytics in analyzing online learning process.

\section{SUMMARY}

The new technology and teacher education fusion mode have important enlightening function, and emphasize the fusion of technology and education service, fusion of human and technology, space and virtual space of entity. Smart education is a new educational form and pattern, which is relied on the deep integration of information and education, and its key goal, is innovation and reform of education. Smart education provides motive power for educational innovation and reform and drives the innovation of educational concepts, teaching pattern, learning concepts, learning styles, educational system, talents training mode, teaching management and educational evaluation. Smart education will support the realization of our Educational Dream well.

Therefore our schools need to change, to adapt to the learning environment. Cloud computing, intelligent terminal is the future of education three information technology innovations. With cloud computing, 3D Print, data, Internet, and other emerging technologies, and build research and production resource sharing among, intelligent, flexible teaching and learning environment. Educational Development with a revolutionary impact of the new technologies in teacher education has an important role.

\section{ACKNOWLEDGMENT}

This work was supported by Research Center for Teacher Education in Western Guangdong(Research and practice of new technology and teacher education fusion mode under the future education space station, No. YXY1406), Foundation of Humanities and Social Sciences Research in Ministry of Education, China (No. 14YJCZH161).

\section{REFERENCES}

[1] Baepler, P. \& Murdoch, C. J. Academic Analytics and Data Mining in Higher Education. International Journal for the Scholarship of Teaching and Learning, 2010, pp. 170-178.

[2] Jim R.Education for a Smarter Planet: The Future of Learning [OL]. http://www.redbooks.ibm.com/redpapers/pdfs/redp4564.pdf.

[3] Info-communications development authority. Empowering learners and engaging minds, through infocomm: Report by iN2015 Education and Learning Sub-Committee[OL].

http://www.ida.gov.sg/doc/About\%20us/About_Us_Level2/2007100510 3551/03 Education and Learning.pdf.

[4] Daniel E, Atkins John B, John S B, et al.National educational technology plan,Office of Educational Technology U.S.Department of Education,2010, pp.101-103.

[5] Smart Australians. Education and innovation in Australia[OL].Nastem Income and Wealth Report. http://www.natsem.canberra.edu.au/ Storage/AMP.NATSEM\%20Income and Wealth Report Smart Australians.pdf.

[6] Smart education smarter india, education sector: Moving toward a digital future[OL]. http://www.biztradeshows.com/sesi/media-center. htmlIndia's. 